\title{
CAPÍTULO 15: O CONCEITO “COMFORT FOOD” APLICADO A CIÊNCIA E TECNOLOGIA DE ALIMENTOS
}

\section{CAPÍTULO 15: EL CONCEPTO "COMFORT FOOD" APLICADO A LA CIENCIA Y TECNOLOGÍA ALIMENTARIA}

\section{CHAPTER 15: THE CONCEPT "COMFORT FOOD" APPLIED TO FOOD SCIENCE AND TECHNOLOGY}

\author{
Neidemarques Casimiro Vieira' ${ }^{1}$; Mônica Tejo Cavalcanti²; Mônica Correia Gonçalves ${ }^{3}$; Thamirys Lorranne \\ Santos Lima4; Inês Maria Barbosa Nunes Queiroga ${ }^{5}$
}

DOI: https://doi.org/10.31692/978-65-88970-18-8.208-227

\begin{abstract}
RESUMO
O conceito Comfort Food configura-se como um meio de incentivo para um retorno pela busca de produtos mais naturais, tradicionais e regionais e que lhe exalte o prazer de uma boa refeição e os sentimentos que os proporcionam. A tentativa de inserção tecnológica ao produzir alimentos por processamentos de identidade regional enraizada possui estreito entendimento com o conceito Comfort Food. Tal conceito busca a valorização artesanal na produção alimentícia, uma vez que além de uma necessidade biológica, alimentar-se funciona como suporte emocional e símbolo cultural. Neste sentido, objetivou-se com a presente pesquisa, realizar uma revisão bibliográfica com o objetivo de mapear a visão científica a cerca do conceito comfort food na tentativa de sugerir a utilização de métodos sensoriais aplicados em pesquisas em Ciência e Tecnologia de Alimentos, para definir e quantificar tais sensações sentidas pelos julgadores ao ingerir o produto em questão. A partir das contribuições aqui estudadas, têm-se que o teste sensorial perfil livre, é um teste possível para se analisar as percepções que o alimento dito como comfort food pode trazer para quem os consome, pois durante o teste os julgadores podem elaborar suas próprias terminologias expressando quais sentimentos e lembranças são sentidas durante o seu consumo, e assim poder quantificar numericamente essas percepções, sendo possível revelar em números as opiniões e informações. Logo, as memórias gustativas são capazes de montar um quebra cabeça acerca do que somos e de onde viemos, sendo possível acessá-las diante de uma simples degustação. Contudo, os pesquisadores poderão estimar numericamente, o quanto essas sensações sensoriais são intensas, marcantes e tipicamente confortáveis.
\end{abstract}

Palavras-Chave: Alimentos gourmet, Comida confortável, Comida tradicional, Comida caseira.

\section{RESUMEN}

El concepto Comfort Food se configura como un medio para incentivar el retorno a la búsqueda de productos más naturales, tradicionales y regionales y que exalta el placer de una buena comida y las sensaciones que los brinda. El intento de inserción tecnológica en la producción de alimentos mediante procesos de identidad regional arraigados tiene un estrecho entendimiento con el concepto Comfort Food. Tal concepto busca la valorización artesanal en la producción de alimentos, ya que además de una necesidad biológica, la alimentación funciona como soporte emocional y símbolo cultural. En este sentido, el objetivo de esta investigación fue realizar una revisión bibliográfica con el fin de mapear la visión científica en torno al concepto de alimentos reconfortantes en un intento de sugerir el uso de métodos sensoriales aplicados en la investigación en Ciencia y Tecnología de Alimentos, para definir y cuantificar los sentimientos que sienten los jueces al ingerir el producto en cuestión. A partir de los aportes aquí estudiados, la prueba sensorial de perfil libre es una prueba posible para analizar las percepciones que la comida dicha como comida reconfortante puede traer a quienes la consumen, pues durante la prueba, los jueces pueden elaborar sus propias terminologías expresando qué sentimientos y

\footnotetext{
${ }^{1}$ Pós-Graduado ,Faculdade Senai da Paraíba, neidemarquescasimiro@ hotmail.com

2 Pesquisadora INSA/MCTI, monica.tejo@insa.gov.br

${ }^{3}$ Docente do Curso de Engenharia de Alimentos, UFCG - Pombal, monica.correia.@professor.ufcg.edu.br

${ }^{4}$ Docente do Curso Técnico Integrado em Alimentos, IFRN-Pau dos Ferros, thamirys.lorranne@ifrn.edu.br

${ }^{5}$ Medicina veterinária, Centro Universitário Dr. Leão Sampaio, inesmaria@leaosampaio.edu.br
} 


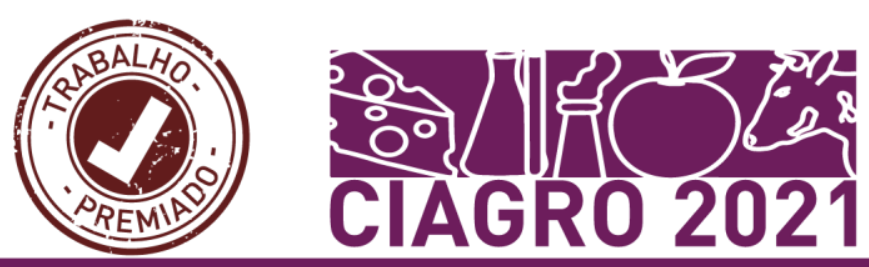

qué sentimientos. los recuerdos se sienten durante su consumo, pudiendo así cuantificar numéricamente esas percepciones, permitiendo revelar opiniones e información en números. Por tanto, las memorias gustativas son capaces de armar un rompecabezas sobre quiénes somos y de dónde venimos, permitiendo acceder a ellas de cara a una simple cata. Sin embargo, los investigadores podrán estimar numéricamente qué tan intensas son estas sensaciones sensoriales, llamativas y típicamente cómodas.

Palabras Clave: Comida gourmet, Comida confortable, Comida tradicional, Comida casera.

\section{ABSTRACT}

The Comfort Food concept is configured as a means of encouraging a return for the search for more natural, traditional and regional products and that exalts the pleasure of a good meal and the feelings that provide them. The attempt at technological insertion when producing food by means of rooted regional identity processing has a close understanding with the Comfort Food concept. Such a concept seeks artisanal valorization in food production, since in addition to a biological need, eating functions as an emotional support and cultural symbol. In this sense, the objective of this research was to carry out a bibliographic review in order to map the scientific vision around the comfort food concept in an attempt to suggest the use of sensory methods applied in research in Food Science and Technology, to define and quantify such feelings felt by the judges when ingesting the product in question. Based on the contributions studied here, the free profile sensory test is a possible test to analyze the perceptions that food said as comfort food can bring to those who consume it, because during the test, the judges can elaborate their own terminologies expressing what feelings and memories are felt during their consumption, and thus being able to numerically quantify those perceptions, making it possible to reveal opinions and information in numbers. Therefore, taste memories are capable of putting together a puzzle about who we are and where we came from, making it possible to access them in the face of a simple tasting. However, researchers will be able to estimate numerically, how intense these sensory sensations are, striking and typically comfortable.

Keywords: Gourmet food, Comfortable food, Traditional food, Homemade food

\section{INTRODUÇÃO}

Nos tempos atuais, devido ao ritmo acelerado de vida, a expansão da indústria e globalização de ingredientes, é cada vez mais evidente a exigência do mercado consumidor por alimentos de fácil e prático preparo, causando a ingestão cada vez maior de produtos industrializados, resultando na maioria das vezes numa refeição solitária e sem sentimentos envolvidos, sejam eles adicionados durante o preparo ou na degustação em si. Movimentos e campanhas têm surgido buscando a valorização por uma alimentação mais simples, natural e saudável, incentivando as pessoas a voltarem à cozinha, retomando o hábito de preparar suas próprias refeições fazendo com que o ato de comer deixe de ser apenas nutricional e passe a ser também sentimental cheio de emoções e temperos frescos, permitindo assim a inter-relação “comida-memórias” de vida (GULARTE, 2016; GIMENES-MINASSE, 2016).

Uma expressão pouco mencionada no Brasil e que se enquadra no movimento Slow food é também o termo inglês Comfort food definido por "comida confortável" que vem com intuito de invocar novas sensações durante o consumo de uma refeição ou bebida, (GIMENES-MINASSE, 2016). Esse conceito vincula-se a apelos de sustentabilidade ambiental e equilíbrio nutricional, extrapolando aspectos culturais e emocionais relacionados ao ato de se alimentar, remetendo ao consumidor bemestar através de memórias de pessoas, lugares e sensações já vividas, onde tal relação resulta em escolhas e hábitos alimentares (GULARTE, 2016). 
A tentativa de inserção tecnológica ao produzir alimentos por processamentos de identidade

regional enraizada possui estreito entendimento com o conceito Comfort Food. Tal conceito busca a valorização artesanal na produção alimentícia, uma vez que além de uma necessidade biológica, alimentar-se funciona como suporte emocional e símbolo cultural (TROISI; WRIGHT, 2016). A conexão do estômago à mente promovida elege saudosos e confortáveis sentimentos no momento da ingestão de alimentos, com ênfase em produtos agroalimentares de identidade local, viabilizando uma alimentação mais saudável e natural (TROISI et al., 2015; GIMENES-MINASSI, 2016). Esta tendência mundial visa resgatar produtos tradicionais, fabricados sob processos seculares e regionalmente artesanais, com o objetivo de conferir comercialização diferenciada com qualidade e identidade territorial (MARCHI, 2015; TROISI; WRIGHT, 2016).

A visão atual do conceito Comfort Food vincula-se a definições filosóficas e sensitivas, por isso, o despertar do meio científico para sua utilização em linhas de pesquisas voltadas à Ciência e Tecnologia de Alimentos deve basear-se em dados oriundos de pesquisas de focos regionais e tratadas de forma específica, a partir de testes sensoriais adequadamente utilizados. Nesse contexto, essa revisão tem por objetivo mapear a visão científica acerca do conceito Comfort Food na tentativa de sugerir a utilização de métodos sensoriais aplicados em pesquisas em Ciência e Tecnologia de Alimentos, para definir e quantificar tais sensações sentidas pelos julgadores ao ingerir o produto em questão

\section{METODOLOGIA}

O delineamento deste estudo caracterizou-se como sendo uma pesquisa descritiva exploratória. Trata-se de uma revisão bibliográfica realizada através de consulta em livros, revistas, artigos científicos, dissertações, monografias, teses e outras produções acadêmicas que abordem a temática em questão, através da busca no Portal de Periódicos da Coordenação de Aperfeiçoamento de Pessoal de Nível Superior (CAPES), no Google Acadêmico, na Scientific Electronic Library Online (SciELO), e na Science Direct. O período de abrangência dos artigos pesquisados, estendeu-se de 2000 a 2017. Foram realizadas pesquisas utilizando as seguintes palavras chaves: Comfort food; comida confortável; comida tradicional; comida caseira e alimentos gourmet em português e em inglês.

\section{RESULTADOS E DISCUSSÃO}

\section{Marcos históricos e conceitos}

Em função da aceleração do ritmo urbano, dado pelo tempo produtivista, é cada vez mais evidente a busca por alimentos industrializados de fácil preparo e, reduzindo assim o 


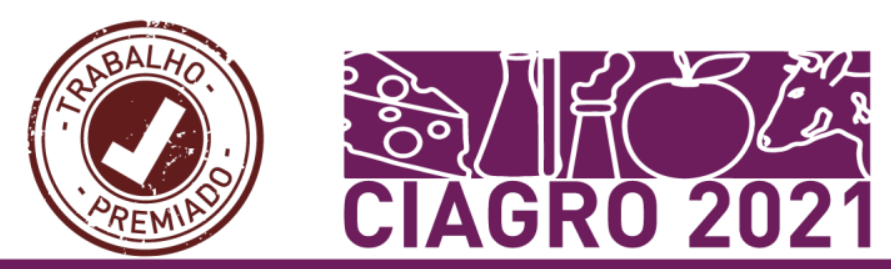

hábito que se tinha de preparar as refeições em casa, adotando uma alimentação a base de produtos fast food como meio de racionalizar o tempo (ANSILIEIRO, 2006).

Em contrapartida a este tipo de movimento que busca realizar refeições de forma imediata surge o conceito de Comfort Food que se trata de um termo originário dos Estados Unidos, que significa "comida confortável" ou "comida que conforta". O termo foi utilizado pela primeira vez em 1977 onde foi incluída sua definição no Webster's Dictionary, que diz se tratar "de um alimento que é gratificante, porque é preparado de forma simples ou tradicional e que faz com a pessoa que o consome lembrar a sua casa, a sua família e amigos". Na década de 1990 o termo foi incorporado ao vocabulário gastronômico americano, fazendo as primeiras associações do alimento de conforto com as sensações emocionais percebidas durante consumo de refeições (MAIRESSE, 2015).

O conceito é pouco percebido em análises brasileiras, mesmo com a valorização e incorporação de termos como 'caseiro' e ‘tradicional' pela indústria alimentícia. Até dicionários nacionais especializados, como o Pequeno Dicionário de Gastronomia (GOMENSORO, 1999), o Pequeno Dicionário da Gula (ALGRANTI, 2000), o Dicionário tradutor de gastronomia em seis línguas (SALDANHA, 2007) e o Gastronomia de A a Z (CATUREGLI, 2011) não abordam o termo Comfort food (GIMENES-MINASSI, 2016). Apesar das pessoas utilizarem a comida em busca de conforto há muito tempo, o termo comfort food só começou a aparecer de forma consistente em revistas, televisão, literatura e publicidade nos últimos anos (LOCHER, 2002). Os livros Histórias e Receitas de uma Vida (COVAS, 2007) e Em Busca do Tempo Perdido (PROUST, 2003) foram os primeiros livros brasileiros a mencionar as sensações e os prazeres que dão razão a uma época, a uma vida e a uma memória através da alimentação.

Bettin (2017) cita em seu trabalho Ganley (1989) que realizou um levantamento deste da década de 50, sobre as influências da ingestão de uma alimentação emocional atrelada a obesidade e buscava compreender essa relação. Os estudos encontrados à cerca da alimentação emocional (KAPLAN; KAPLAN, 1957; STUNKARD, 1959; FINK; GOTTESFELD; GLICKMAN, 1962; KOLLAR; ATKINSON; ALBIN, 1968) relaciona esse fenômeno com fatores psicológicos, e sustenta a teoria que indivíduos obesos eram os que mais tinham acesso à ingestão desse tipo de alimentação em respostas a sensações negativaslestresse emocional ou como uma tentativa de conseguir uma resposta emocional positiva. Inicialmente se tinham o alimento de conforto como aquele que não é saudável, carente de valor nutricional ou rico em carboidratos, calorias e gordura. Em contrapartida outros autores (GULARTE, 2016; SILVA, 2016; WANSINK, 2014) debatem a comida de conforto como aquela que é feita de forma simples, utilizando produtos naturais, que represente uma cultura elou região e principalmente 


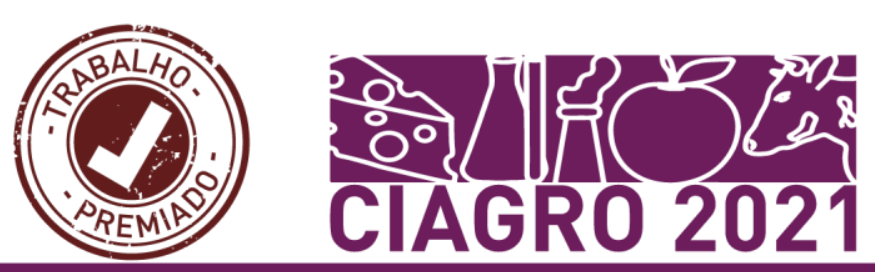

que faça uma ligação com a família gerando sensações positivas e que lhe traga conforto (TROISI; WRIGHT, 2016).

Wansink (2014) diretor do Food and Brand Lab da Universidade de Illinois em Urbana, estudou os alimentos de conforto e buscou respostas para três questões-chave: 1- O que são alimentos de conforto? 2- Quando as pessoas comem alimentos de conforto? 3- Como os alimentos de conforto são formados? Através desses estudos pode-se obter uma base de informações para responder os seus questionamentos. Para os entrevistados comfort food tratase de uma categoria de alimentação tradicional, podendo ser classificado relativamente como natural, caseiro ou mesmo "saudável", sendo relevante não o seu valor nutricional, mas sim o conforto psicológico que estes alimentos fornecem e o que eles representam. A entrevista revelou que as pessoas estavam mais propensas a procurar alimentos de conforto quando estavam felizes ou quando queriam comemorar ou recompensar-se por algo. As escolhas alimentares e as preferências por alimentos de conforto foram determinantes devido a associações que são passadas através do produto, ou por identificação de personalidade, ou seja, esses alimentos estão associados a sentimentos específicos que os entrevistados gostavam de recordar ou recapturar, estando eles também associados à lembrança de um ente querido ou a um evento especifico, ou simplesmente por terem aspectos do produto que eles veem consistente com sua personalidade.

Apesar se tratar de um conceito recente e pouco estudado no Brasil, se enquadra em um tema rico de informações, estando dentro de um vasto campo de estudos, sendo assim necessária uma abordagem multidisciplinar. Para cada área, se tem uma definição, que de forma geral, o conceito é o mesmo, modificando apenas as palavras (VALE, 2014; GIMENES-MINASSE, 2016). Para a Psicologia Comfort food trata-se de alimentos que são consumidos em momentos de emoções positivas ou para aumentar esses sentimentos e para aliviar os efeitos psicológicos negativos, trata-se de uma alimentação específica, que quando consumida em uma determinada situação pode nos trazer um conforto psicológico (SILVA, 2016). Para a gastronomia afetiva, trata-se de uma relação do homem com as percepções e emoções que o alimento pode lhe proporcionar, através de sensações gustativas, olfativas e sensoriais (MAIRESSE, 2015).

Em Vale (2014) são vistos três conceitos diferentes: para a antropologia, uma alimentação de conforto é um veículo fundamental para reuniões de famílias ou comunidade em volta da mesa e que faz reviver seus costumes, cultura e origem; para a sociologia, a alimentação nostálgica esta interligada a momentos de festividades, mais do que o ato de sentar à mesa para comer, é em termos simbólicos, o expressar de sentimentos de carinho e de amor; já para a biologia os estados de humor também são influenciados por alguns tipos de alimentos, 


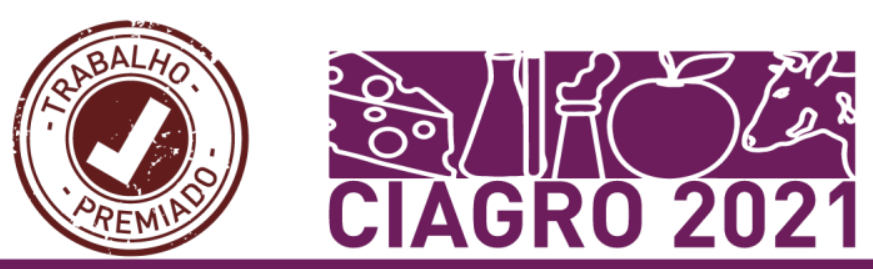

aqueles que são ricos em hidratos de carbono contribuem para um aumento da produção de triptofano, um aminoácido essencial que faz aumentar o nível de serotonina (neurotransmissor do cérebro) em nosso corpo e responsável por produzir um estado de humor positivo.

\section{Hábitos Alimentares}

A alimentação é uma das mais complexas necessidades básicas para a sobrevivência do ser humano, sendo o consumo de alimentos uma necessidade vital por fornecer ao indivíduo os nutrientes e a energia indispensável para a extensão da vida. (ANSILIEIRO, 2006). Os hábitos alimentares são definidos pela junção das seguintes decisões: o que comer, quando comer, onde, como e com quem comer (GIMENES-MINASSE, 2016). Além de seus aspectos médicos ou biológicos, a alimentação pode ser vista por seus aspectos econômicos, sociais, políticos, culturais, sexuais, estético e entre outros (BRAGA, 2004; ANSILIEIRO, 2006). Desde muito cedo, o desenvolvimento do comportamento alimentar começa a se ampliar, há evidências que os primeiros hábitos alimentares surgem durante a gravidez e amamentação, havendo influências das escolhas alimentares que a mãe tem durante a gestação, que por sua vez pode influenciar as preferências alimentares da criança (FRANCISCO, 2016).

Os comportamentos alimentares e a escolha de alimentos variam entre homens e mulheres. Para os alimentos de conforto um estudo realizado por WANSINK e SANGERMAN (2000); DUBE e LEBEJ e LU (2005) determinaram que as mulheres preferem lanches práticos como seu alimento de conforto e com altos teores de calorias, como biscoito, chocolates, sorvetes, bolos e estes consumidos frequentemente em respostas para as emoções negativas do cotidiano. Já os homens, tendem a consumir os alimentos de conforto em resposta a emoções positivas, dando preferência a uma boa refeição a base de carnes e farinhas, como macarrão e pizza. Outra diferença também percebida durante os estudos foi o tipo de escolha de alimentos frente às diferentes faixas etárias de idade, pessoas mais jovens enquanto experimentavam de sensações negativas preferiam consumir mais lanches, que pessoas com mais de 55 anos de idade, e estas consumiam seus alimentos de conforto quando experimentavam por emoções positivas. Essas escolhas podem ser explicadas devido a expectativa de que com a idade, aprendemos a regular melhor nossas emoções (SARMIENTO; MARCELINO; FAGAN, 2011). 
Os alimentos estão presentes em todos os momentos, principalmente positivos, pois dificilmente se comemora algo sem a presença de alguma comida ou bebida, e na maioria das vezes é feita para externar amor, carinho e agradecimento para a quem temos apreço, assim uma resposta emocional é motivada, gerando um elo entre as pessoas, trazendo emoções, vivendo e revivendo momentos nostálgicos (SILVA, 2016). A memória gustativa é formada por nossas lembranças e momentos especiais que são guardados em nosso cérebro e que podemos reviver esses momentos quando provamos algo que nos faz reviver momentos passados. No livro a Comida caseira (OLIVIER, 2015), a memória gustativa tem o poder de nos transportar para outro tempo e/ou nos levar para outros lugares, esse sentimento é tão forte que podemos sentir cheiros, experimentar sensações e reviver sentimentos como se estivéssemos no local para onde fomos transportados.

De forma geral o conceito de memória está intimamente relacionado com o que é lembrado do passado, o que é memorizado, e utilizado para construir o presente, essas memórias podem ser tanto de carácter individual como de um grupo (SMITH, 2004). É possível voltar ao passado, nem que seja por breves momentos, as memórias gustativas são pedaços de nossas vidas que guardamos em nós mesmos que podemos acessar com uma simples porção de refeição (GULARTE, 2016). Este mesmo autor define comida como aquela na qual preza as sensações e, ainda mais, os prazeres que são sentidos e que dão razão a uma época, a uma vida e a uma memória.

Locher et al (2005) realizaram um estudo com 264 estudantes de graduação de Universidades, através de entrevistas, onde foi solicitado que os entrevistados citassem quais alimentos o fazem se sentir bem ou que lhes fornecessem conforto e em seguida explicassem porque escolheram tais alimentos. $\mathrm{O}$ autor descobriu duas semelhanças para todos os alimentos que foram citados como comfort food, que todos os produtos estavam intimamente ligados a memórias familiares, atrelados a sentimentos de saudades, e que os entrevistados consumiam esses alimentos quando estavam com sentimentos negativos com intuito de reviver momentos especiais e amenizar a saudade sentida dos familiares.

\section{Alimentos tradicionais}

Um conjunto de práticas alimentares determinadas ao longo do tempo por uma sociedade passa a identificá-la e muitas vezes, quando enraíza, se torna patrimônio cultural. A comida considerada como típica ou regional representa uma tradição, os costumes de um povo 


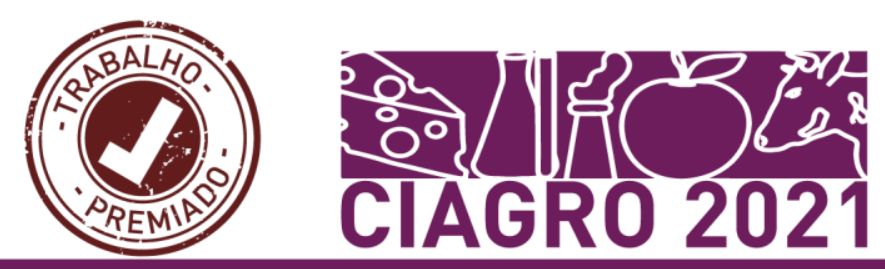

ou região, apesar de influenciada por fatores ambientais, geográficos e pelo tipo de colonização,

o mesmo alimento pode ser utilizado em regiões diferentes, porém o seu modo de preparo e os temperos utilizados, os diferenciam (SONATI; VILARTA; SILVA, 2009).

Gimenes (2006) realizou uma reflexão sobre a valorização das comidas tradicionais pelo Instituto de Patrimônio Histórico e Artístico Nacional (IPHAN) e a atividade turística no Brasil. $\mathrm{O}$ autor evidência algumas iniciativas relacionadas ao reconhecimento do patrimônio gastronômico como patrimônio cultural, desta forma, lançando uma contribuição no sentido de ressaltar a importância da gastronomia como manifestação cultural, apontando perspectivas de fortalecimento do turismo cultural a partir da oferta gastronômica. Nesse sentido o autor pautase a importância das manifestações gastronômicas por acreditar que o alimento é fonte de informações preciosas, podendo identificar uma cultura, um estilo de vida, um acontecimento ou uma época.

Um dos aspectos mais importantes é o fato de que o alimento é capaz de definir um povo ou um grupo, criar uma identidade própria para uma região ou comunidade, marcar estilos regionais e nacionais. Falando de culinária nacional, no Brasil podemos falar em um prato que representa toda a nação quando se considera o "feijão com arroz", trata-se de uma refeição, consumida em todas as regiões do país, é o prato síntese da sociedade brasileira e tem um sentido unificador (ANSILIEIRO, 2006).

Apesar da forte representatividade do "arroz com feijão", as cozinhas regionais sobrevivem fortemente enraizadas e em sua enorme variedade nas diversas regiões brasileiras. Determinadas regiões se caracterizam por famosos pratos, que ficam intimamente mais associados a sua região de origem e seus habitantes, tais como o pão de queijo para o mineiro, o baião de dois para o Ceará, o churrasco para o gaúcho e o vatapá e acarajé para a Bahia. Existem pratos regionais que ficam restritos aos seus locais de origem não apenas pela dificuldade de se conseguir determinado ingrediente, mas principalmente pelos fatores culturais, que fazem com que certas preparações sejam ou não bem aceitas por grupos de outras regiões (SILVA, 2000).

\section{Alimentos tipicamente regionais}

A cozinha brasileira é uma integração das diferentes influências portuguesas, afro e indígena, sendo assim possível que cada região desenvolva uma cultura alimentar peculiar e característica de seu povo (SONATI; VILARTA; SILVA, 2009). 
No Norte, a mandioca é o alimento típico da região e utilizado em diversas preparações, bem como diversos peixes que também são a base para outros pratos típicos. O Tacacá; Tucupi; Maniçoba; Açaí com tapioca, carnes assadas de jacaré e tartarugas, castanha do Pará, guaraná são muitas das iguarias que são consumidas e apreciadas nessa região (SONATI; VILARTA; SILVA, 2009).

De acordo com Costa (2016) o Tucupi é um produto muito consumido na região Norte, porém pouco utilizado como matéria-prima para elaboração de produtos, por isso, foi realizado um estudo do processo de produtos a base de Tucupi. O tucupi concentrado foi utilizado em diferentes proporções na formulação de três produtos: molho cremoso, condimento em pó e caldos em tabletes e em seguida foram realizados os testes quanto a aceitação dos atributos sensoriais, impressão global e intenção de compra para os produtos elaborados. Como resultados os valores do índice de aceitabilidade foram superiores a 70\% para todos os produtos, o que indica que apresentaram uma boa aceitação. E isto é confirmado pelo alto grau de intenção de compra para estes produtos, onde os julgadores manifestaram possibilidade de compra de 99\% para o molho cremoso de tucupi, $100 \%$ para o condimento em pó e $98 \%$ para caldos em tabletes. Com isso, o autor sugeriu os produtos elaborados como uma alternativa promissora para agregação de valor ao tucupi.

Fritsch e Silva e Degáspari (2015) desenvolveram formulações de barra de chocolate adicionado de guaraná em pó, com o objetivo de aproveitar as suas propriedades estimulantes, decorrentes da cafeína presente em sua composição. As formulações protótipos foram submetidas a testes de análise sensorial de preferência de comparação múltipla, empregando-se o método de escala hedônica com nove pontos. Como resultado as três formulações não apresentaram diferença significativa com relação aos parâmetros analisados de odor, sabor e textura. Apresentaram também boa aceitação pelos degustadores, com médias variando entre 7,47 (equivalente a "gostei regularmente") e 8,40 (equivalente a "gostei muito" - "gostei muitíssimo"). O resultado final do estudo demonstrou ser possível a obtenção de um chocolate em barra, adicionado de guaraná em pó com grande potencial para proporcionar propriedades estimulantes aos consumidores, sendo que esta comprovação deverá ser ainda investigada através de outro trabalho de pesquisa específico voltado para análise farmacodinâmica.

\section{Cozinha da Região Nordeste}

Na região Nordeste são utilizados como alimentos básicos a mandioca, batata doce, feijão, carne de sol, bovina e caprina, rapadura, milho, leite, manteiga, peixes e frutos do mar. 


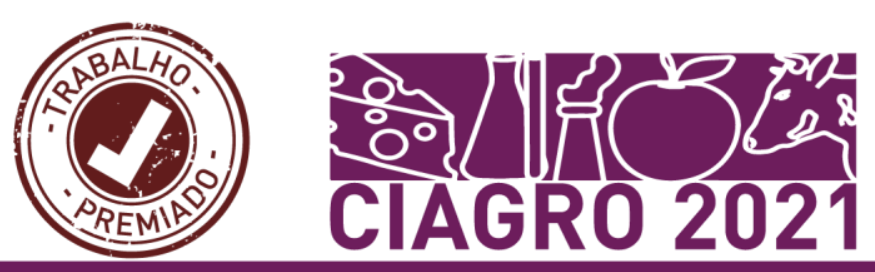

Pratos típicos apreciados é a polenta com leite; galinha de cabidela; Angu e cuscuz; acarajé, vatapá e doces a base de frutas da região (SONATI; VILARTA; SILVA, 2009).

Santos et al (2012), desenvolveram e analisaram sensorialmente um sorvete de mandioca com intuito de agregar valor comercial ao aipim criando um novo produto para servir de alternativa para os produtores. Preliminarmente foram realizados ensaios de formulação, na tentativa de padronizar os teores de açúcar, massa das raízes e água do produto até se chegar a uma formulação final. O sorvete foi avaliado sensorialmente, através dos atributos de aparência, aroma, sabor, doçura e textura, utilizando escala hedônica estruturada de sete pontos e também avaliando a sua intenção de compra. Todas as variáveis analisadas no teste sensorial apresentaram medias que variaram de 5,67 a 6,33 sendo o sorvete qualificado como "gostei muito" a "gostei muitíssimo". Com isso o autor pode concluir que a mandioca é uma boa matéria-prima para produção de sorvete, sensorialmente aceitável pelos consumidores, já que $88,89 \%$ dos provadores comprariam o produto. Portanto o sorvete a base de mandioca constitui uma excelente forma para diversificação da produção e mais uma alternativa para a comercialização e valorização desta matéria-prima que é bastante apreciada na região Nordeste do Brasil.

Queiroz et al (2013); Brasil et al (2014) desenvolveram estudos sobre a utilização dos subprodutos do abate, vísceras e sangue como uma opção de incremento para a oferta de produtos cárneos derivado de caprinos. Queiroz et al (2013) realizou a caracterização físicoquímica e indicadores de qualidade higiênico-sanitária em buchada caprina comercializado em João Pessoa - PB, enquanto Brasil et al (2014) estudou o valor nutricional e a qualidade microbiológica do sarapatel caprino comercializado nessa mesma região. Ambas as autoras evidenciaram o aproveitamento dos subprodutos do abate na elaboração de novos produtos cárneos processados, como uma forma de agregar valor a esses produtos devido ao seu excelente valor nutritivo e fonte de proteína. Nesse contexto pode-se perceber a valorização por produtos tidos como regionais ou tradicionais e como alternativa de incremento das opções de produtos derivados caprinos.

\section{Cozinha da Região Centro-Oeste}

O Centro-oeste é uma região que consome produtos da pesca e da caça, frutas e hortaliças típicas da região como: pequi, pitanga, jatobá, jenipapo entre outras. Alguns pratos típicos são o peixe na telha, quibebe, carne com banana, costelinha, bolinhos de arroz, feijão tropeiro, carne seca, toucinho e pamonha (SONATI; VILARTA; SILVA, 2009). 
Carvalho (2008) elaborou preparações regionais saudáveis do Centro-oeste brasileiro,

onde inicialmente realizou uma pesquisa bibliográfica sobre as frutas e hortaliças mais apreciada na região, logo após modificou 20 receitas culinárias utilizando essas matérias-primas e em seguida realizou testes sensoriais para aceitabilidade dessas novas formulações. Para a escolha das receitas o autor baseou-se nos pratos típicos servidos com maior frequência em restaurantes de autosserviço da região Centro-oeste. Considerou-se a viabilidade das modificações das receitas originais visando adequação nutricional e propondo a redução da utilização de ingredientes lipídicos e restrição da quantidade de sódio e açúcar nas elaborações. As frutas e hortaliças utilizadas foram o pequi, milho verde, gueroba, araticum, baru, cagaita, pitanga, jatobá, maracujá, marmelada de cachorro e jenipapo. Algumas das receitas desenvolvidas foram: Monjica de pintado, quibebe de abóbora, feijão tropeiro, geléia de cagaita, purê de maracujá entre outros. De maneira geral, quanto à análise sensorial, 80\% das 20 receitas desenvolvidas ficaram com percentual de aprovação superior a 75\%. Portanto a utilização de produtos regionais além da implicação nutricional tem como consequência o incentivo ao consumo de frutas e hortaliças por meio de preparações saudáveis e sensorialmente agradáveis.

\section{Cozinha da Região Sul}

O Sul tem o churrasco gaúcho como principal prato típico dessa região, tendo ainda forte influência nos hábitos alimentares as carnes defumadas, salames, massas em geral, pão de leite, sopas, pães, queijos, sobremesas a base de frutas e bebida típica da região como o chimarrão (SONATI; VILARTA; SILVA, 2009).

Tonollo e Palezi (2016) elaboraram salame de frango com adição de ervas finas, teor de sal reduzido e fermentado pelo probiótico kefir, na intenção de criar um produto inovador que possa atender as exigências do consumidor que busca por produtos com mais nutrientes, menos gorduras e menos sódio, ou seja, alimentos saudáveis e que promovam o bem-estar. O autor também buscou criar uma alternativa para as pessoas que não são adeptas ao salame de derivados bovinos e suínos, buscando manter as mesmas características do produto tradicional, porém com uma matéria-prima diferenciada. Foram realizadas as análises microbiológicas e físico-químicas e todos os resultados obtidos estavam em acordo com as legislações. Na análise sensorial foi possível identificar que $82,7 \%$ dos consumidores aprovaram o salame de frango, tornando-o mais uma possível opção para a produção de salames.

Santos (2016) em sua dissertação realizou o estudo da qualidade físico-química e sensorial de cerveja elaborado com adição de erva-mate tipo chimarrão. Como resultados 


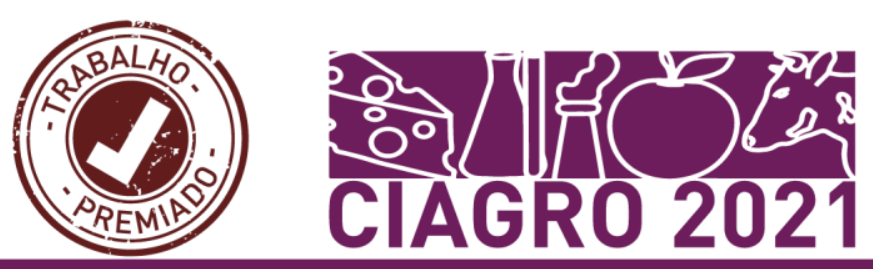

obtidos, as formulações enquadram-se na legislação, recebendo a classificação de cerveja leve, comum ou extra. Através do trabalho realizado pode ser visto a utilização de erva-mate como uma forma de agregar valor a cerveja, diversificando o mercado de bebidas alcoólicas, já que esse produto é consumido não só na região sul, mas sim em todo território brasileiro. Outro fator importante foi à utilização dessa matéria-prima como valorização de um produto tipicamente regional.

\section{Cozinha da Região Sudeste}

Na região sudeste tem-se a tradição da moqueca de peixe cozida em panela de barro; feijoada; tutu de feijão; angu com quiabo; curau; paelha; quibes; esfihas entre outros (SONATI; VILARTA; SILVA, 2009).

Rosa et al (2016) realizou estudo sobre a elaboração de esfihas de frango adicionadas de farinha de casca de berinjela e analisou o produto quanto a sua composição físico-química e sensorial. O trabalho evidenciou a utilização de partes de alimentos normalmente desprezadas, como cascas, talos e folhas, na forma de ingredientes, aproveitando os seus elevados fatores nutricionais com efeitos benéficos na saúde e na prevenção de doenças. O autor relata que a farinha da casca da berinjela demonstrou ser um produto viável para elaboração e melhoramento de novos produtos por ser obtido por meio de tecnologia simples e apresentar perfil nutricional bastante significativo, como o elevado teor de antocianinas. Foram elaboradas 5 formulações com diferentes porcentagens de farinha da casca da berinjela e em seguida realizadas as análises. Com o trabalho pode-se comprovar que um nível de adição de até $5 \%$ de farinha da casca de berinjela em esfihas foi bem aceito pelos julgadores, obtendo-se aceitação sensorial semelhante ao de um produto tradicional, além de ter melhorado o perfil nutricional do produto. Portanto a farinha da casca da berinjela torna-se um potencial ingrediente para adição em esfihas e similares, agregando valor ao produto e como forma de aproveitamento do aporte nutricional presente na casca da berinjela.

\section{Alimentos Gourmet}

Uma nova tendência no mercado e que tem aumentado fortemente nos últimos anos são as ofertas por alimentos gourmetizados que também se enquadram no movimento comfort food. O que inicialmente tratava-se de bens de consumo considerados sofisticados e onerosos, hoje são produtos já encontrados facilmente em supermercados e lanchonetes. Os produtos 


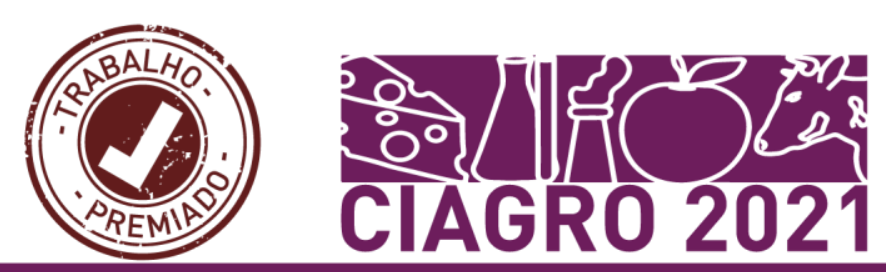

considerados gourmets não há uma definição aceita, possuem qualidades específicas que os

diferenciam dos demais, chamados tradicionais. Em suma os alimentos da categoria gourmet são diferentes dos produtos industrializados e tem valor agregado, prezam pela qualidade e origem das matérias-primas, apresentação do produto, bem como pela sua disponibilidade e exclusividade (NUNES, 2011).

Um dos produtos mais consumido no Brasil, independentemente da região são os hambúrgueres, devido ao aumento da necessidade de alimentação fora do lar e a rotina cada vez mais corrida, esse prato muitas vezes se torna uma refeição constante para boa parte da população por ser de rápido preparo e ser um produto facilmente encontrado em lanchonetes. Um mercado que vem ganhando força em todo o país e que vem conseguindo disputar com grandes redes de fast-foods são as hambúrguerias artesanais, por se tratar de um produto diferenciado do padrão (MOREIRA JÚNIOR, 2016). Este mesmo autor estudou qual o perfil dos consumidores de hambúrguer gourmet em João Pessoa - PB e buscou entender o que influencia a escolha de consumo por parte do individuo para com esse novo produto. Pode-se concluir, no estudo, que no passado se tratava de um produto ainda pouco conhecido na cidade, que vem ganhado destaque e preferência pelos consumidores e que a renda é o fator que mais influência para o consumo desse tipo de produto.

Os doces também figuram entre os alimentos preferenciais para o consumo, um doce que vem facilmente sendo gourmetizado é o brigadeiro, sua popularidade se tornou incontestável e faz parte da cultura nacional. O brigadeiro saiu de sua apresentação tradicional em forma de bolinha e ganhou novos modos de apresentação, sendo eles oferecidos em embalagens criativas e até com certo requinte. A análise sensorial constitui importante ferramenta de avaliação de brigadeiros e pode identificar diferenças cruciais para os padrões de qualidade, como por exemplo, o sabor e o aspecto dos doces requintados despontam como meio de avaliação dos consumidores de lojas de brigadeiro gourmet (SALES; ELLIOT, 2016).

O Jornal A Gazeta, coluna Prazer \& Cia, realizou testes sensoriais em doce brigadeiro de uma loja gourmet em Vitória no Espírito Santo, onde contou com a presença de um especialista americano. Este mesmo autor em seu projeto realizou entrevistas com consumidores frequentes dessa guloseima, onde $97 \%$ dos entrevistados consomem esse doce para ampliar o seu humor, que é percebido durante a sua ingestão.

Gelados comestíveis abrangem toda uma gama de produtos, popularmente denominados sorvetes, e que abrange outros produtos como picolés e sobremesas. Esses produtos têm em comum o fato de ser consumidos em sua forma congelada e apresentar as mais variadas composições e sabores. Seguindo a tendência de produtos caseiros e de qualidade premium, 


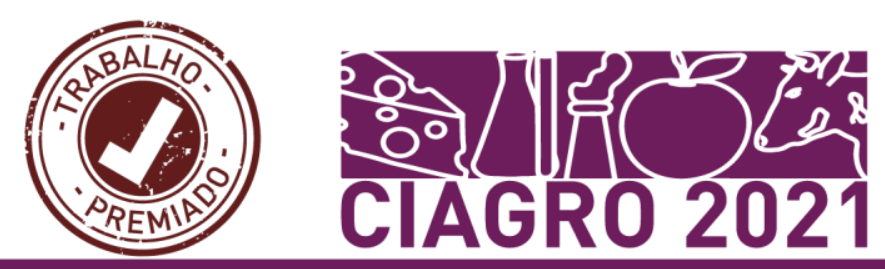

alguns produtos têm-se destacado e ganhado espaço no mercado. Um exemplo são as paletas

mexicanas (RENHE; WEISBERG; PEREIRA, 2015). São uma espécie de picolé, bem maior que o de costume e que possui recheio cremoso. $\mathrm{O}$ seu diferencial são os ingredientes naturais e de alta qualidade unidos ao preparo artesanal do produto. São totalmente livres de corantes ou conservantes químicos e possuem tanto sabores tradicionais como morango, abacaxi, coco e limão quanto opções mais exóticas como hibisco com framboesa ou abacaxi com pimenta. Essa nova tendência pareceu como uma oportunidade para empreendedores, atendendo um mercado de consumo que exige “coisas novas” e de qualidade (LOURENÇO, 2016).

\section{Análise Sensorial}

Entre os métodos utilizados na análise sensorial descritiva tem-se o teste de Perfil livre (Free-Choice Profiling). Reconhecido como a metodologia mais inovadora de se conduzir uma análise descritiva. É assim chamado por permitir ao julgador a liberdade de usar termos descritivos conforme sua percepção durante o teste. Apresenta como vantagem o curto tempo para aplicação, pois emprega somente uma explanação sobre o levantamento dos atributos, o uso da escala e das fichas de avaliação (STONE; SIDEL, 2004). O número de participantes pode variar de acordo com a familiaridade com o produto, disponibilidade de tempo e experiência (KITZBERGER et al., 2010). Está técnica vem sendo bastante utilizada por conseguir diminuir ou até mesmo eliminar as sessões de treinamento dos analistas, que são realizadas em outros métodos. A única cobrança é para que os provadores sejam claros e objetivos nas definições e sejam capazes de utilizar escalas de intensidade e desenvolver listas de atributos (VERRUMA-BERNARDI; DAMÁSIO, 2004).

Outro proveito do perfil livre é a possibilidade de os julgadores adicionarem ou retirarem termos da lista originalmente desenvolvida durante o processo de avaliação dos produtos. Além disso, permite a diferenciação de atributos entre os provadores, a verificação daquelas características sensoriais importantes para a maioria dos consumidores (MARCELLINI, 2005).

Através desse teste sensorial seria possível analisar as percepções que o alimento dito como comfort food pode trazer para quem os consomem, pois durante o teste os julgadores podem elaborar suas próprias terminologias, gerando uma lista de termos que mesmo sendo diferentes entre eles, mas que expressam quais sentimentos, quais lembranças podem ser sentidas durante o seu consumo, e assim poder quantificar numericamente essas percepções, sendo possível revelar em números as opiniões e informações para então adquirir uma análise 


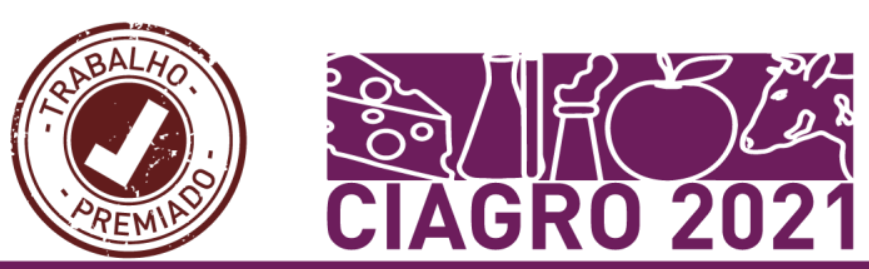

de dados e, em seguida, chegar a uma conclusão, entretanto ainda não se tem trabalhos que quantifiquem esses resultados (MOREIRA JUNIOR, 2016).

Texeira (2016) desenvolveu um teste sensorial de almôndega da carne mecanicamente separada de tilápia do Nilo, pelo método de perfil livre. Para o desenvolvimento da terminologia descritiva realizou-se duas sessões e, em cada uma delas, apresentaram-se duas amostras de almôndegas, solicitando-se que o provador anotasse as similaridades e as diferenças entre ambas. Após as sessões de levantamento de termos descritores, foram definidas as listas de atributos de cada provador e assim elaboraram-se as fichas com as escalas de intensidade para cada parâmetro analisado. Os dados obtidos do perfil livre foram analisados através do método de Análise de Compomentes Comuns e Pesos Específicos (CCSWA) para obter-se uma distribuição de consenso dos julgadores para a caracterização das amostras. Com isso o autor pode realizar as correlações significativas entre os atributos sensoriais levantados pelos provadores.

Verruma-Bernardi e Damásio (2004) em seu estudo objetivaram verificar a eficiência da técnica do Perfil Livre na descrição das características sensoriais de aparência e textura do queijo Mozarela de leite de búfala em 2 diferentes métodos. As análises foram realizadas para os 2 processamentos do queijo em 3 ensaios, com intuito de verificar as diferenças e similaridades do produto. Os autores concluíram que o método do perfil livre foi eficiente para o estudo, onde houve uma alta repetibilidade e concordância entre os provadores, e também entre os processamentos.

Marcellini (2005) propõe em seu trabalho a associação de duas técnicas descritivas: perfil livre e análise de tempo-intensidade, além de teste de aceitação e de equivalência de doçura, para traçar um perfil sensorial completo do suco de abacaxi adoçado com os principais edulcorantes. Utilizando a técnica do perfil livre o autor mostrou que esse método foi bastante adequado para análise dos sucos adoçados, pois pode verificar as semelhanças entre as características de cada amostra através da proximidade entre as mesmas nas dimensões analisadas.

Leal et al (2016) realizaram estudo sobre a aplicação da técnica de perfil livre em mel para concursos de produtos agrícolas. Tais concursos teve como objetivo mostrar as características sensoriais e físico-químicas da produção de mel e incentivar as boas práticas de fabricação e técnicas de apicultura, como forma de valorização do produto e de reconhecer os esforços dos produtores. Foi realizada a caracterização físico-química de umidade, Hidroximetilfurfural (HMF) e acidez para conferir a qualidade do mel e em seguida a análise sensorial dos méis foi realizada por meio da técnica de perfil livre. Foram avaliadas 21 amostras, 
das quais 19 apresentaram qualidade físico-química em conformidade com a legislação. As

amostras foram avaliadas para identificar os principais atributos de aparência, aroma, sabor e textura. Os provadores identificaram um grande número de atributos, principalmente para aroma e sabor, devido à sua facilidade de percepção. Observou-se maior consenso na descrição dos atributos de aparência e textura. O teste de perfil livre foi fundamental para descrição e classificação dos méis alcançando o consenso entre os julgadores.

\section{CONSIDERAÇÕES FINAIS}

Este estudo reportou a intensa utilização de alimentos como remetentes às sensações agradáveis e saudosas, de valor inestimável para o portador. Memórias gustativas são capazes de montar um quebra cabeça acerca do que somos e de onde viemos, sendo possível acessá-las diante de uma simples degustação. Este trabalho sugere que o conceito Comfort Food pode ser atrelado às pesquisas acadêmico-científicas, a partir da utilização do teste sensorial de Perfil Livre, sendo possível que os julgadores utilizem terminologias originalmente pessoais, e assim, pesquisadores poderão estimar numericamente, o quanto essas sensações sensoriais são intensas, marcantes e tipicamente confortáveis.

\section{REFERÊNCIAS}

A Gazeta: on line, Espirito Santo, 13 out. 2011. Disponível em: http://gazetaonline.globo.com/_conteudo/2011/10/noticias/a_gazeta/prazer_cia_ag/989076teste-do-brigadeiro.html. Acesso em: 17 dez. de 2017.

ALGRANTI, Márcia. Pequeno dicionário da Gula. Rio de Janeiro: Record, 2000.

ANSILIERO, G. O movimento Slow Food: A relação entre o homem, alimento e Meio ambiente. 45f. Monografia (especialização) - Universidade de Brasília. Centro de Excelência em Turismo. Brasília, 2006.

BETTIN, B. P. C. Fatores associados e instrumentos de avaliação da alimentação emocional: uma revisão narrativa da literatura. Monografia - Curso de Nutrição. Faculdade de Medicina. Universidade Federal do Rio Grande do Sul. Porto Alegre, 2017.

BRAGA, V. Cultura alimentar: contribuições da antropologia da alimentação, Saúde em Revista, v.4, n.13, p.37-44, 2004.

BRASIL, L. M. S., QUEIROZ, A., SILVA, J., BEZERRA, T., ARCANJO, N., MAGNANI, M., SOUZA, E., MADRUGA, M. Sarapatel caprino: valor nutricional e qualidade microbiológica. Molecules. 2014. 


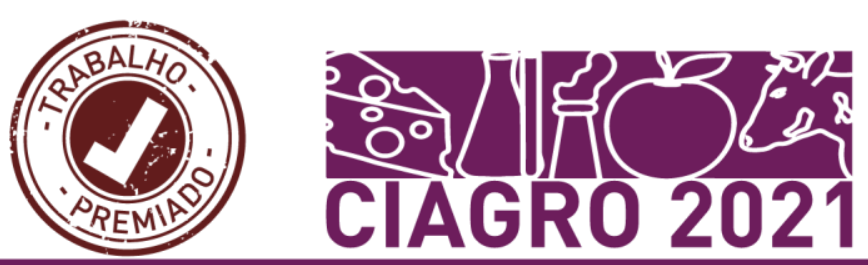

CARVAlHO, M. V. O. Preparações Regionais Saudáveis do Centro Oeste Brasileiro. Monografia (especialização). Centro de excelência em Turismo. Universidade de Brasília Brasília, 2008.

CATUREGLI, M. G. Gastronomia de A a Z. São Paulo: Aleph, 2011.

COSTA, T.S. Estudo do processo de concentração do tucupi e da elaboração de produtos a base de tucupi concentrado. Tese (Doutorado) - Universidade Federal do Pará. Instituto de Tecnologia. Programa de Pós-Graduação em Ciência e Tecnologia de Alimentos, Belém, 2016.

COVAS, L. Histórias e Receitas de uma Vida. Brasil: Editora Global \& Fundação Mario Covas, São Paulo 2007.

DUBE, L., LEBEL, J., LU, J. "Affect asymmetry and comfort food consumption." Physiology \& Behavior, p. 559-567, 2005.

FINK, G., GOTTESFELD, H., \& GLICKMAN, L. The "super-obese" patient. Journal of the Hillside Hospital, p. 97-11, 1962.

FRANCISCO, B. F. Estilos, práticas e percepções e preocupações parentais relacionadas com os hábitos alimentares da criança pré-escolar. Tese de Doutorado. Faculdade de Psicologia. Universidade de Lisboa. 2016.

FRITSCH, F. C.; SILVA, M. S.; DEGÁSPARI, C. H. Desenvolvimento e análise sensorial de formulações de chocolate em barra adicionadas de guaraná em pó. Saúde, v. 1, n. 13, 2015.

GANLEY, R. M. Emotion and Eating in Obesity: A Review of the Literature. International Journal of Eating Disorders, v. 8, n. 3, p. 343-361, 1989.

GIMENES, M. H. S. G. Patrimônio Gastronômico, Patrimônio Turístico: uma reflexão introdutória sobre a valorização das comidas tradicionais pelo IPHAN e a atividade turística no Brasil. Seminário de Pesquisa em Turismo no Mercosul, v. 4, p. 1-15, 2006.

GIMENES-MINASSE, M. H. S. G. Comfort food: sobre conceitos e principais características. Contextos da Alimentação. Revista de Comportamento, Cultura e Sociedade, v. 4, n.2, p. 92-102, 2016.

GOMENSORO, M. L. Pequeno dicionário de gastronomia. Rio de Janeiro: Objetiva, 1999.

GULARTE, J. P. A. Memória gustativa: comida, um caminho até uma lembrança querida. Revista Turismo, Gastronomia e desenvolvimento na região das missões - Brasil - 2016.

KAPLAN, H. L., \& KAPLAN, H. S. The psychosomatic concept of obesity. Journal of Nervous and Mental Disease, v. 125, p. 181-201, 1957.

KITZBERGER, C. S. G.; SCHOLZ, M. B. S.; SILVA, J. B. G. D.; BENASSI, M. T. Caracterização sensorial de cafés arábicas de diferentes cultivares produzidos nas mesmas condições edafoclimáticas. Brazilian Journal of Food Technology, v. 6, n. 1, p. 39-48, 2010. 


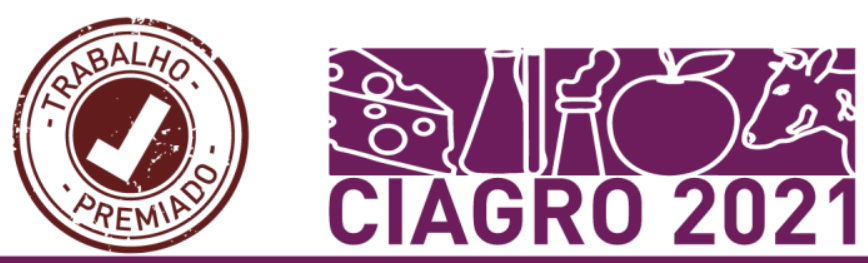

KOLLAR, E. J., ATKINSON, R. M., ALBIN, D. L. The effectiveness of fasting in the treatment of superobesity. Psychosomatics, v. 10, p. 125-135, 1968.

LEAL, S. F. L. S.; KITZBERGER, C. S. G.; SCHOLZ, M. B. S.; OLIVEIRA, A. F. Análise Sensorial do Mel por Meio da Técnica de Perfil Livre e sua Aplicação em Concursos, p. 191218. In: Tópicos em Ciências e Tecnologia de Alimentos: Resultados de Pesquisas Acadêmicas - Vol. 1. São Paulo: Blucher, 2016.

LOCHER, J.; YOELS, W.; MAURER, D.; VAN ELLS, J. Comfort foods: an exploratory journey into the social and emotional significance of food. Food \& Foodways, v.13, n.4, p.273297, 2005.

LOCHER, J. Comfort food. In: KATZ, Sean. (ed). Encyclopedia of Food and Culture. New York: Charles Scribner's Son, 2002.

LOURENÇO, E. U. O Fenômeno da gourmetização. Monografia - Faculdade de Comunicação. Universidade de Brasília. Brasília, 2016.

MAIRESSE, L. D. K. O conceito comfort food entre dois tipos de estabelecimentos de alimentação na cidade de Porto Alegre. Monografia (especialização) - Universidade do Vale do Rio dos Sinos Unisinos. Curso de Gestão e Gastronomia em serviços de alimentação. Porto Alegre 2015.

MARCELLINI, P. S. Caracterização sensorial por perfil livre e análise tempo-intensidade de suco de abacaxi (Ananas comosus L.Merril) reconstituído e adoçado com diferentes adoçantes. Tese (Doutorado) - Faculdade de engenharia de alimentos. Universidade Estadual de Campinas. Campinas - 2005.

MARCHI, J. F. Development strategy of local agri-food products: typical regional cheese. Anais: V Congresso Brasileiro de Engenharia de Produção.2015.

MOREIRA JÚNIOR, R. C. S. Análise das preferências do consumidor de hambúrguer gourmet. Trabalho de conclusão de curso (Graduação em Administração) - Universidade Federal da Paraíba - João Pessoa, 2016.

NUNES, S. I. C. Produtos alimentares Gourmet: perspectivas do consumidor, do fornecedor e do cozinheiro profissional. Tese de Doutorado. Instituto Superior de Economia e Gestão. Universidade Técnica de Lisboa. Lisboa, 2011.

OLIVER, J. Comida Caseira. Edição 1. Brasil: Globo Estilo ed., 2015.

PROUST, M. Em busca do tempo perdido. 1, Brasil: Zahar, 2003. p.76.

QUEIROZ, A. L. M.; BRASIL, L. M. S.; SILVA, J.; MAGNANI, M.; SOUZA, E. L.; MADRUGA, M. S. Microbiological and nutritional quality of "buchada caprina", an edible goat meat by-product. Small Ruminant Research, v. 115, p. 62-66, 2013.

RENHE, I.R. T.; WEISBERG, E.; PEREIRA, D. B. C. Indústria de gelados comestíveis no Brasil. Informe Agropecuário, v.36, n.284, p.81-86, 2015. 


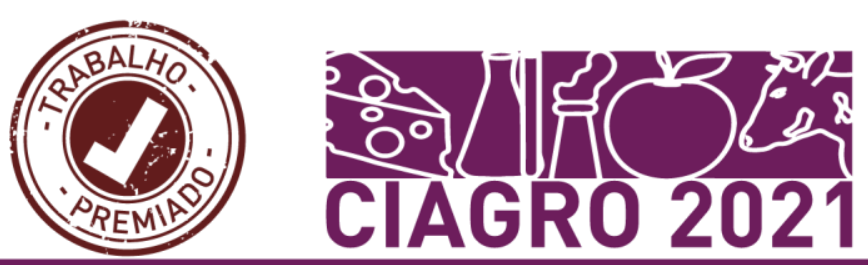

ROSA, P. A., RODRIGUES, B. M., SANTOS, N. M., CANDIDO, C. J., SANTOS, E. F., NOVELLO, D. Elaboração de esfihas de frango adicionadas de farinha de casca de berinjela: análise físico-química e sensorial. Revista Uniabeu, v. 9, n. 21, p. 200-213, 2016.

SALDANHA, R. M. Dicionário tradutor de gastronomia em seis línguas. São Paulo:AB, 2007.

SALES, P. R.; ELLIOT, L. G. Instrumento de avaliação por Consumidores para Empreendimentos de Doces Gourmet: construção e validação. Revista Meta: Avaliação, v. 8, n. 23, p. 380-409, 2016.

SANTOS, C. O. Elaboração de cerveja com adição de erva-mate (Ilex paraguariensis A.St. Hil.): qualidade físico-química e sensorial. Dissertação (Mestrado) 129p. Universidade Federal de Santa Maria. Centro de Ciências Rurais. Programa de Pós- Graduação em Ciência e Tecnologia dos Alimentos. Rio Grande do Sul, 2016.

SANTOS, D. B.; MACHADO, M. S.; CONCEIÇÃO, A. L. S.; BELO, G. O.; CARDOSO, R. L. Elaboração e análises físico-química, microbiológica e sensorial de sorvete de mandioca de mesa (manihotesculenta, Crantz). Enciclopédia Biosfera, v. 8, n. 15, p. 821-831, 2012.

SARMIENTO, R.; MARCELINO, J.; FAGAN, J. M. Comfort Foods: The Roles Food Plays in Our Lives. 2011.

SILVA, M. C. G. A alimentação e a culinária de italiana no médio vale Itajaí. Artigo apresentado no Fórum Comida e Simbolismo, na 22 $2^{\mathrm{a}}$ Reunião da Associação Brasileira de Antropologia. 2000.

SILVA, M. P. O. Comfort Food - Alimentando as memórias e sensações. Revista Contribuciones a las Ciencias Sociales. 2016. En línea: http://www.eumed.net/rev/cccss/2016/01/food.html Acesso realizado: 17 de janeiro de 2021.

SMITH, A. Heteroglossia, common sense and social memory. American Ethnologist, v. 31, n.2, p. 251-69, 2004.

SONATI, J. G.; VILARTA, R.; SILVA, C. C. Influências culinárias e diversidade cultural da identidade brasileira: imigração, regionalização e suas comidas. Mendes RT, Vilarta R, Gutierrez GL. organizadores. Qualidade de vida e cultura alimentar. Campinas: Ipes, p. 137-147, 2009.

STONE, H.; SIDEL, J. L. Descriptive Analysis. In: STONE, H.; SIDEL, J. L. (ed.). Food Science and Technology. San Diego: Academic Press, 2004, p. 201-245. (Sensory Evaluation Practices, 3. ed.).

STUNKARD, A. J. Eating patterns and obesity. Psychiatric Quarterly, 33, 284-29

TEIXEIRA, H. Descrição sensorial de almôndega de CMS de tilápia-do-Nilo (Oreochromis niloticus), pelo método de Perfil Livre. 2016. 41 f. Trabalho de Conclusão de Curso (Graduação) - Curso superior de Engenharia de Alimentos. Universidade Tecnológica Federal do Paraná, Campo Mourão, 1959. 


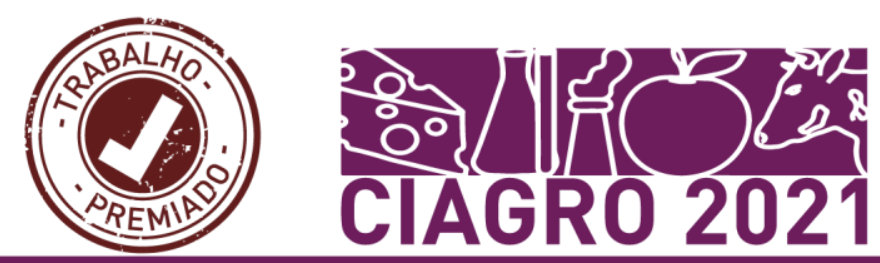

TONOLLO, M.; PALEZI, S. C. Salame de frango funcional com adição de ervas finas e reduzido teor de sal. Seminário de Iniciação Científica, Seminário Integrado de Ensino, Pesquisa e Extensão e Mostra Universitária. Unoesc \& Ciência - ACET Joaçaba, v. 7, n. 2, p. 247-254, jul./dez. 2016

TROISI, J. D.; SHIRA, G.; JAYE, L. D.; ALYSSA, G. Threatened belonging and preference for comfort food among the securely attached. Appetite, v. 90, p. 64, 2015.

TROISI, J. D.; WRIGHT, J. W. C. Comfort Food: Nourishing Our Collective Stomachs and Our Collective Minds. Teaching of Psychology, v. 44, p. 78-84, 2016.

VALE, V. C. F. T. A nostalgia de alimentos no contexto de uma experiência gastronômica. 2014. Tese de Doutorado. Especialização em Marketing e Estratégia. Faculdade de Economia da Universidade do Porto. 2014.

VERRUMA-BERNARDI, M. R.; DAMÁSIO, M. H. Análise descritiva de perfil livre em queijo mozarela de leite de búfala. Ciência e Tecnologia de Alimentos, v. 24, n. 4, p. 536-542, 2004.

WANSINK, B. Engineering comfort foods. American Demographics, p. 66-67, 2014. 